\title{
UNWANTED EFFECTS WITHIN A COGNITIVE BEHAVIORAL THERAPY GROUP IN COMPARISON WITH A RECREATIONAL GROUP - A CLUSTER-RANDOMIZED CONTROLLED TRIAL
}

\author{
Beate Muschalla ${ }^{1}$, Bianka Flöge ${ }^{2,3}$ \& Michael Linden ${ }^{3}$ \\ ${ }^{I}$ Technische Universität Braunschweig, Department of Psychology, Braunschweig, Germany \\ ${ }^{2}$ Brandenburgklinik, Bernau, Germany \\ ${ }^{3}$ Research Group Psychosomatic Rehabilitation at the Charité University Medicine, Berlin, Germany \\ received: 3.7.2018; \\ revised: 5.2.2019; \\ accepted: 15.5 .2020
}

\section{SUMMARY}

Background: Group interventions can have negative effects for patients with anxiety disorders. Stimuli which provoke side effects may be the group setting, the content, or the interaction between the participants in the group. This study is the first to report negative effects from a cognitive behavioral group intervention, in comparison with an unspecific, recreational group for anxiety patients.

Subjects and methods: 107 patients with work-related anxiety disorders were randomized to either a cognitive behavioral group therapy (work-coping group WG) or an unspecific group encounter aimed at increasing recreational activities (recreational group $R G)$. Patients completed the Unwanted Events in Group Therapy Scale (UE-G scale).

Results: In the work-coping group, $41.9 \%$ of the patients reported at least one relevant side effect, as compared to $28.9 \%$ in the recreational group. These included an increase in the perception of anxiety and work-problems, feelings of exposure to criticism and the development of negative views on group therapy as such.

Conclusions: This is the first randomized, controlled, therapy study in anxiety patients to systematically investigate side effects. Work-coping group interventions have, despite their useful main effects, specific negative effects, when compared with group encounters. Group psychotherapists or group moderators should be aware of the potential side effects in anxiety patients.

Key words: side effects - cognitive behavioural therapy - exposure therapy - anxiety - recreational therapy

$* * * * *$

\section{INTRODUCTION}

It has long been known that psychotherapy interventions can cause negative effects (Barlow 2005, Bergin et al. 1963, Lambert \& Ogles 2004, Linden \& Strass 2013, Berk \& Parker 2009, Dimijian \& Hollon 2010). Workdirected interventions may also cause unintended effects (Noordik et al. 2013, van Vilstern et al. 2015). The side effects of psychotherapeutic interventions are defined as adverse treatment reactions (ATR) due to correct (!) treatment (Linden 2013). Adverse treatment reactions must be distinguished from non-response, from other unwanted events that occur in parallel but independently of treatment, or from the consequences of malpractice.

Side effects must be expected in group psychotherapeutic interventions particularly. In addition to the basic psychotherapeutic intervention, there are also group dynamics and interactions between group participants (Sipos \& Schweiger 2003). Other patients in the group may or may not give helpful or misleading advice. By observing others, patients may learn how bad their own work-problem or illness is and how little can be done. Group participants may breach confidentiality, fight or pick on each other. The room, the number of people or the setting, may cause claustrophobia or other anxiety reactions. In summary, the group setting, the other patients, the therapist, and the therapeutic interventions are all capable of causing burdens to the patient
(Roback 2000, Burlingame et al. 2004, Strauß \& Mattke 2012). Yalom et al (1971) found that $18.7 \%$ of patients in encounter groups dropped out, and that $9.4 \%$ of those who completed, reported enduring significant negative outcomes caused by the group therapy. A high-risk leadership style was identified, which is characterized by high stimulus input, aggression, charisma, intrusiveness, and an individual instead of a group, focus (Yalom et al. 1971). In a study by Smokowski et al. (1999), 40\% of the 83 participants of social work groups reported negative experiences such as perceiving the leader as a perpetrator, having intense emotional reactions or being discouraged from pursuing further help. Qualitative research has identified critical incidents in group interventions like failure to attend or arriving late, feeling discounted or misunderstood, lack of self-disclosure, member disconnection, member attack, or other unwanted activities (Doxsee \& Kivlighan 1994). Therapy drop-outs result, according to Kordy \& Senf (1992), from isolation in the group, large group size, joining an existing, closed group as a new participant, low motivation and chronic somatic symptoms.

Based on such empirical research, Burlingame et al. (2004) developed a model to help identify the negative effects of group interventions. First, there is the type of intervention, such as educational groups, experiential therapy, exposure treatment, or cognitive interventions, which may have different effects (Linden \& Hautzinger 
2011, Bisson et al. 1997, van Gent \& Zwaart 1991, Linden 2013). Further dimensions are group and interaction processes, therapist or moderator characteristics, participants' characteristics, setting and structural conditions.

There are some methodological problems in assessing side effects (Linden 2013, Strauß \& Mattke 2012). It is not always clear whether the treatment effects are negative or positive, e.g. quitting the workplace. It is also difficult to differentiate between negative treatment effects, the negative course of an illness, or the consequences of other factors such as problems at home. It is even more difficult to determine whether these are negative treatment effects, or negative effects of false treatment.

To control for such unspecific, negative effects, controlled clinical trials are necessary. We carried out a randomized, controlled study with work-anxiety patients on the effects of cognitive behavioral group therapy (work-coping group), in comparison with an unspecific recreational patients' meeting. In addition to workrelated, positive, main outcomes (Muschalla et al. 2014, 2016), this also included a targeted assessment of treatment-related burdens, which allows the study of negative effects from the specific work-coping intervention, while controlling for unspecific complaints.

\section{SUBJECTS AND METHODS}

\section{Setting and participants}

The study was performed in a German rehabilitation hospital in which people with chronic illness and workproblems are treated with the aim of vocational reintegration. Patients were treated with a variety of medical and rehabilitation interventions according to their individual needs. This did not include any specific psychotherapeutic sessions or groups. As for some patients, the return to work is hindered by work-anxiety (Linden \& Muschalla 2007), the primary goal of the present study was to assess work-related anxieties, provide a structured, cognitive behavioral, group therapy (work-coping group) and test its effects, in comparison with an unspecific recreational group meeting (Muschalla et al. 2014, 2016). This also allowed treatment specific side effects to be studied.

After admission to the hospital, the patients were seen by a state-licensed psychotherapist (BM) and asked to fill in a screening form about work-related anxieties (Muschalla et al. 2014, 2016). Patients who reported increased work-anxiety for at least two of the nine work-anxiety items, were then assessed using the structured Work Anxiety Interview (Linden \& Muschalla 2007). 347 patients fulfilled the inclusion criteria for the work-anxiety therapy study. A sub-sample of 111 patients was randomly selected and asked to participate in an additional interview about side effects from the group intervention; 107 agreed to participate. 52\% (WG $52 \%$, RG $51 \%$ ) were female, their average age was 50.2 years (WG 48.9; RG 51.8), 81.9\% were currently employed (WG 80.0\%; RG 84.0\%).

Patients gave their written, informed consent and the study was approved by the ethics committee of the University of Potsdam and the Internal Review Board of the Federal German Pension Fund.

\section{Intervention and control group}

For organizational reasons, a cluster randomization was carried out: For the first three months all patients were offered one type of intervention and in the next three months, the other type. Both groups were slowopen and had on average, 5-8 patients, the group meetings lasted 90 minutes and were manual-guided (Muschalla et al. 2014, 2016). In each session, new patients joined and others finished their hospital stay and left the group. The therapist was a psychiatrist with a special training in the treatment manual, who did all the group sessions in both treatment conditions, so that there was no difference in regard to the therapist. The therapy was regularly supervised by a state-licensed behavioral therapist (B.M.), with special knowledge of the treatment of patients with work-related anxiety.

The work-coping group (WG) was a cognitive behavioral therapy using established anxiety treatment approaches such as exposure, training in symptom tolerance, problem solving and cognitive reframing. Patients were guided to confront themselves with workrelated problems.

In the recreational group (RG), the topics work and anxiety were explicitly not mentioned. The focus was on well-being, recreation, and leisure time. The patients were encouraged to play games and engage in pleasant, leisure activities, like painting, telling jokes, watching comedy films, or cooking.

Inpatient treatment lasted about three weeks. There were two group sessions per week, which gave an average of $M=4.2(S D=2.4)$ sessions per patient (WG $M=4.2(S D=2.6)$, RG $M=4.3 S D=2.2)$. These are the conditions of routine care in rehabilitation. The results of this study therefore allow conclusions to be drawn about the side effects of a short-term, cognitive behavioral group therapy in work-anxiety inpatients. As both groups were lead by the same therapist, had the same size and setting, the same duration, and the same type of patients, the only difference was the focus and content of the group treatment. This allows different complaints about treatment burdens to be attributed to the group content and structure.

\section{Assessment of side effects}

The assessment of negative treatment effects was performed by a trained study psychologist (B.F.), who met with each patient individually. The patients had participated in $M=2.75(S D=1.11)$ therapy sessions when the interview took place (AG $M=2.82(S D=1.26)$, RG $M=2.64(S D=0.86)$. 


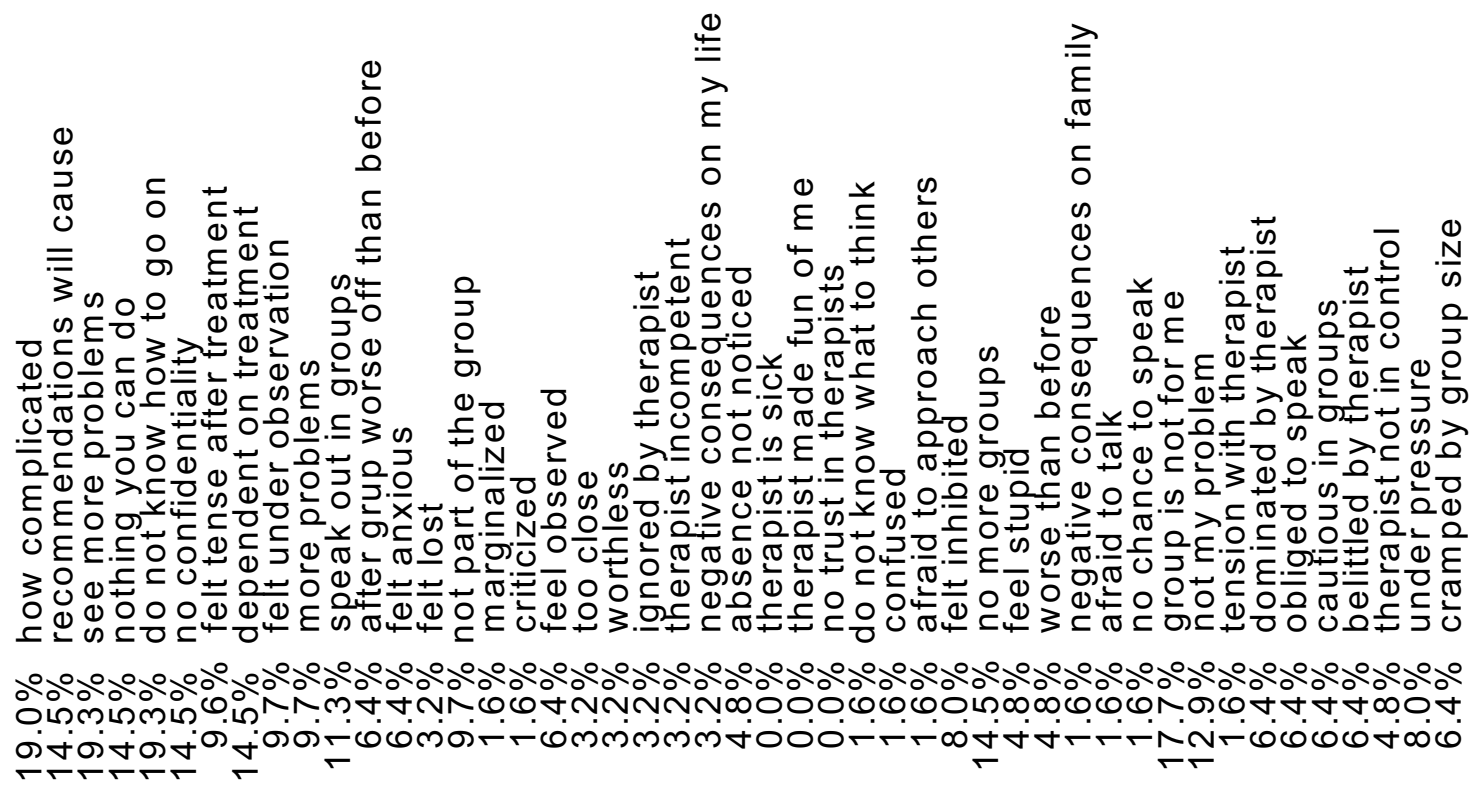

$\hat{\sim}$

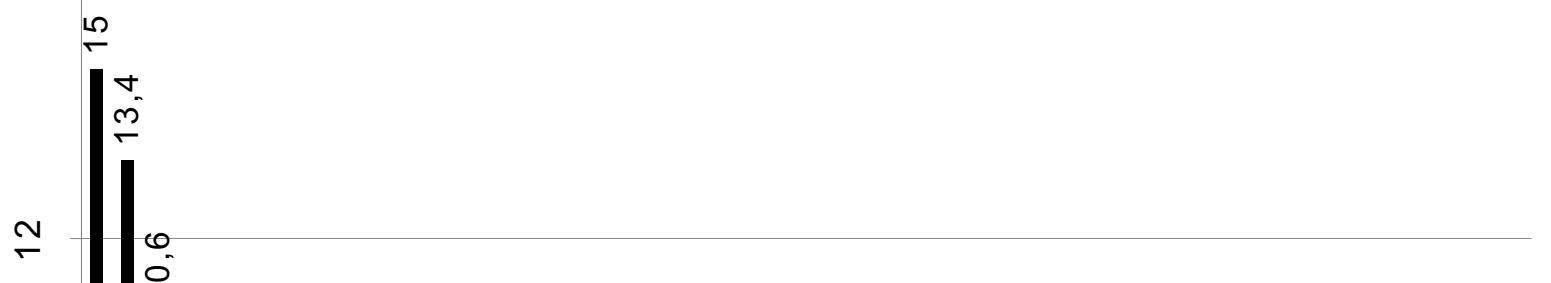

$\stackrel{N}{\sim}$

$\sim$

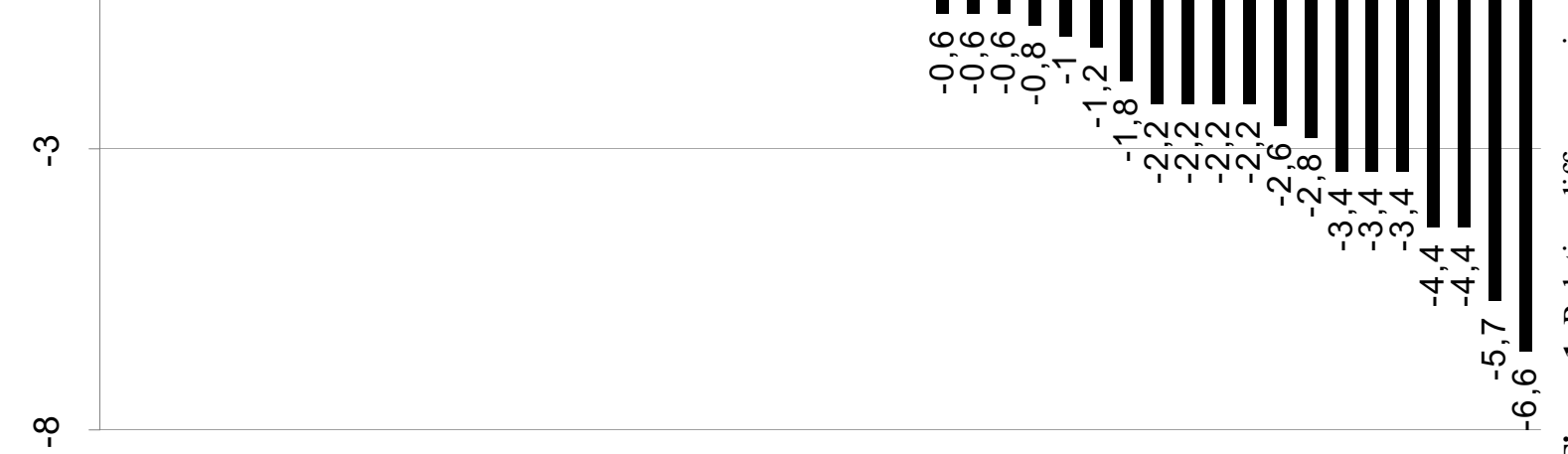


Patients were first asked to fill in the Unwanted Events in Group Therapy Scale (UE-G scale) (Linden et al. 2015) which has 47 items (Figure 1). In order not to elicit global complaints, the patients were asked to think about specific elements of the group and say whether they felt burdened by the room and group size, content of the therapy sessions, participants, therapist, lessons learned or general experience. There is empirical evidence that the questions are well understood (Muschalla et al. 2014; Linden et al. 2015). Patients can answer each item using a five-step Likert scale: $0=\operatorname{did}$ not occur, 1 = did occur, but was hardly burdensome, 2 = did occur and was clearly burdensome, $3=$ did occur and was very burdensome, $4=$ did occur and was extremely burdensome.

\section{RESULTS}

In both groups, almost all the patients experienced at least one side effect (i.e. at least one item $>0$, WG $91.9 \%$ $(\mathrm{n}=62)$; RG $\left.88.9 \%(\mathrm{n}=45) ; \chi^{2}=0.286(1), p=0.593\right)$. When considering severe side effects (ratings 2-4), there were still $41.9 \%$ in the $\mathrm{WG}$ and $28.9 \%$ in the $\mathrm{RG}$ $\left(\chi^{2}=1.916(1), p=0.193\right)$.

Figure 1 shows the percentages of severe side effects (ratings 2-4) for the WG and the comparison with the RG.

Considering the combined results from both groups, the most frequent overall complaints were that patients said "After the group therapy, I see more problems than before (19.3\%)", "I do not know how to get on $(19.3 \%)$ ", "I now see how complicated everything is (19.0\%)", "Group therapy is not for me (17.7\%)", "I will not attend groups in the future (14.5\%)", "I do not trust the confidentiality in groups $(14.5 \%)$ ", "If I were to follow the recommendations, it would lead to problems (14.5\%)", "I have learned that nothing can be done" (14.5\%), "I see that I am dependent on therapy and cannot master my life without it (14.5\%)", "I felt forced to speak in the group (11.3\%)".

When comparing both groups, an increased rate of burdens could be seen in the work-coping group results: "After the group therapy, I now see how complicated everything is $(15.0 \%)$ ", "If I were to follow the recommendations, it would lead to problems (13.4\%)", "I now feel worse than before $(10.7 \%)$, "I see more problems than before $(10.6 \%)$ ", "I have learned that nothing can be done" $(10.0 \%)$, "I do not know how to get on $(8.3 \%)$ ", "I do not trust the confidentiality in groups (7.5\%)", "I felt tense during the group session $(7.4 \%)$, "I see that I am dependent on therapy and cannot master my life without (5.7\%)", "I felt under observation in the group session $(5.3 \%)$, "I now see more problems than before" $(5.3 \%)$, or less often, feelings of being marginalized or that one's own workproblems have not been addressed. Work-coping therapy gives a feeling that work and health problems are complex and difficult to handle.
The data also show which group encounters burdens can be ameliorated by targeted treatment. The feelings of being cramped in the group (-6.6\%), of being under pressure $(5.7 \%)$, and of being obliged to speak $(3.4 \%)$ are higher in unstructured group encounters. The same is true for feelings that the therapist is not in control of the encounter $(-4.4 \%)$, or even being belittled by the therapist $(4.4 \%)$, and that you have to be cautious in the group (-3.4\%). Unstructured group encounters give a feeling of insecurity within the group.

\section{DISCUSSION}

This is to our knowledge, the first study which systematically investigates the side effects of group psychotherapy within a randomized, controlled, comparison of different group interventions in work-anxiety patients, i.e. a targeted cognitive behavioral work-coping group and an unspecific group encounter with playing games, which can be considered a psychotherapeutic placebo.

The first important finding is that almost all patients, i.e. about $90 \%$, complain of some side effects. Even when only relevant burdens are considered ("did occur and was clearly burdensome" (rating 2), "did occur and was very burdensome" (rating 3), "did occur and was extremely burdensome" (rating 4), almost one out of three patients complained of least one side effect.

This rate is higher than that reported in the earlier literature, which ranges from 3-15\% (Mohr 1995, Lambert \& Ogles 2004). Some studies focus on specific negative effects lsuch as deterioration, but do not consider a broader spectrum of side effects (Bystedt et al. 2014). Furthermore, it is clear that the rate of side effects is very dependent on the definition, classification and methodology used (Linden 2013). Rates are bound to be higher in structured assessments which actively ask patients for side effects, compared to spontaneously reported complaints. In the present study, we used the Unwanted Events in Group Therapy Scale (Linden et al. 2015) which cues the assessment of burdens by reminding patients of specific group factors like the room, the therapist's behavior, discussion content, other participants etc. This may stimulate memories and therefore result in higher reports than if the question were to be posed in more general terms. Our methodology has a good validity, as we have tested whether patients understand the questions properly in independent samples with qualitative interviews (Linden et al. 2015).

Nevertheless, the rate of side effects is of relevance for occupational medicine practice. Similarly to drug therapy, side effects from work-coping interventions are the rule rather than the exception. Side effects are frequent, unavoidable and not an expression of incorrect treatment, but an integral part of regular treatment. This is especially true for group interventions, which may produce even more side effects than single setting therapy (Roback 2000, Lambert \& Ogles 2004). Thus 
moderators need to be aware of side effects in their group interventions and control not only therapist behavior, therapeutic focus, type of interventions, but also the behavior of group members and their interaction. As side effects may be related to the interaction between patients or with the therapist, it can be assumed that patients do not always report them to their therapist, in order not to appear critical of the therapist or his/her actions (Haupt \& Linden 2011). Therefore special, active efforts are needed to monitor side effects.

The second important finding is that there are side effects in both a work-coping group and a recreational group setting. The difference in the side effects of workcoping groups and recreational groups is due to the content of the two groups. Thus, the data suggest that not all groups are the same, but, that their content makes a difference. Specific therapeutic interventions have specific side effects.

When looking at the "placebo-group" (RG), the primary burden for patients is that they have to sit together with other, strange people and are expected to make contact. This is a kind of social exposure and may be especially difficult for anxious people (Aderka et al. 2012). They may feel tense and stressed because there are so many people in the room and have the feeling that they are expected to make small talk and do not know what to say. They also do not see that the therapist is helping as he does not coordinate the encounter and control what is going on. The therapist may even be seen as somebody who is not paying attention to their work and health problems and instead joking with patients, which can be experienced as not being taken seriously. Even in such unstructured group encounters, relevant side effects can occur, because patients conclude that they do not want any more group treatments in the future. Therefore, clinicians should also consider the potential side effects of such groups when these are suggested as programs for recreation from work.

Some of these problems can be overcome in a specific therapy group, which is lead by a therapist and which has a clear topic for discussion. But, this specific therapeutic intervention can also have even more serious side effects. In cognitive behavioral therapy, an important strategy is to analyze anxiety-provoking situations. This can be understood as exposure in sensu. Exposure provokes anxiety (Haines et al. 2002) and in this sense our results confirm that confronting one's own with work-anxiety and work-problems can provoke more anxiety and more problems. The problem is that in some patients, this does not regress in the further course of therapy. Discussing work-problems and how to cope with anxiety-provoking situations at work, can also result in a more detailed view of the work-problem while also subjectively feeling unable to cope with it. About one in five patients reports a feeling of inadequacy after attending the work-coping group. The most prominent side effect of this type of treatment is demoralization and hopelessness. This can be considered a serious problem, as it aggravates the patients' pathological perspective.

Do these results mean that work-coping group therapy is never good? In the large therapy study, the work-anxiety intervention was proved to lead to positive outcomes, in that it increases work-coping perception and decreases the duration of further sick leave (Muschalla et al. 2014, 2016). But, research is needed on how to overcome the side effects which occur during treatment.

In this study, the short period of treatment must be considered. Because the length of the inpatient stay was three weeks, only about four group sessions could be done. This is normal in everyday practice. It may be that side effects might vanish after longer periods of workcoping treatment. After six therapy sessions, patients in the work-coping group report increased work-coping perception (Muschalla et al. 2014). Further studies are needed to clarify the development of side effects. Thus, the question arises whether these short-term interventions are permissible, if the side effects are taken into account. A justification for using work-coping groups, despite the occurrence of side effects, is that in the end, patients achieve important, positive outcomes from treatment: In the present therapy study, patients in the work-coping group, were in the end, more convinced of being able to cope with work (Muschalla et al. 2014), or they returned to work earlier (Muschalla et al. 2016).

There are no follow up data so whether the side effects are transient or persistent and how they influence the further course of the illness and future treatments, cannot be stated. Studies will be needed to further investigate whether these negative side effects can be reduced during a long-term group therapy. Furthermore the question of the long-term impact of the negative side effects on the anxiety-disorder and daily life of the patient needs consideration.

There was only one therapist. Although there is no indication that she had a high-risk leadership style and the treatment was manual-guided and closely supervised, we cannot say whether other therapists would have had the same results. Further studies with larger numbers of different group moderators are needed. Also other settings, such as work capacity coaching (Schermuly et al. 2014) or return-to-work processes, should be considered.

\section{CONCLUSIONS}

Group settings impose burdens on patients per se. Specific therapeutic interventions, such as specific work-coping groups, have specific side effects. A cognitive behavioral therapy for work-coping and workanxiety reduction can, during its course, provoke more anxiety and feelings of inadequacy. Good group moderators must be aware of side effects, as a prerequisite for dealing with them. 


\section{Acknowledgements:}

The manuscript underwent professional proofreading for English language by Kelly $\mathrm{GmbH}$ www.korrekturplus-lektorat.de.

\section{Funding:}

This research has been financially supported by the German Federal Pension Fund. 8011-106-31/31.107

\section{Conflict of interest: None.}

\section{Contribution of individual authors:}

Beate Muschalla: development, implementation and supervision of the group therapy, design of the study, development of the evaluation measure, literature searches and analyses, statistical analysis, interpretation of data, writing of the manuscript

Bianka Flöge: accompanying the group therapies, data collection, literature searches

Michael Linden: development of the evaluation measure, completing the statistical analysis, proofreading the manuscript.

\section{References}

1. Aderka IM, Hofman SG, Nickerson A, Hermesh H, Gilboa-Schechtman E \& Marom S: Functional impairment in social anxiety disorder. J Anx Disorders 2012; 26:393-400

2. Barlow S: Analytische und Psychodynamische Gruppenpsychotherapie: Gibt es dazu Daten? Gruppenpsychotherapie Gruppendynamik 2005; 41:239-266

3. Bergin AE, Murray EJ, Truax $C B$ \& Shoben EJ: The effects of psychotherapy: Negative results revisited. Journal of Counselling Psychology 1963; 3:244-250

4. Berk $M \&$ Parker $G$ : The elephant on the couch: sideeffects of psychotherapy. Aust N Z J Psychiatry 2009; 43:787-794

5. Bisson JH, Jenkins PL, Alexander $J$ \& Binnister $C$ : Randomized controlled trial of psychological debriefing for victims of acute burn trauma. Br J Psychiatry 1997; 171:78-81

6. Burlingame GM, MacKenzie KR \& Strauß B: Evidencebased small group treatments; in Lambert $M$, Bergin AE, Garfield SL (Eds). Handbook of psychotherapy and behavior change (5th ed.). New York, Wiley \& Sons, 2004

7. Bystedt $S$, Rozental A, Andersson G, Böttcher $J$ \& Carlbring P: Clinicians' Perspectives on Negative Effects of Psychological Treatments. Cogn Behav Ther 2014; 43:319-331

8. Dimidjian $S$ \& Hollon SD: How would we know if psychotherapy were harmful? American Psychologist 2010; 65:21-33

9. Doxsee D \& Kivlighan DM: Hindering Events in Interpersonal Relations Groups for Counselors Trainees. $J$ Couns Dev 1994; 72:621-626

10. Flöge B, Fay D, Jöbges M, Linden $M \&$ Muschalla B: Nebenwirkungen von Ergotherapiegruppen. Fortschritte der Neurologie und Psychiatrie 2016; 84:729-732
11. Haines J, Williams C \& Carson JM: Workplace Phobia: Psychological and psychophysiological Mechanisms. Int J Stress Manage 2002; 9:129-145

12. Haupt ML \& Linden M: Nebenwirkungen und Nebenwirkungserfassung in der Psychotherapie. Das ECRSATR-Schema. Psychotherapie und Sozialwissenschaft $2011 ; 13: 9-28$

13. Lambert MJ \& Ogles BM: The efficacy and effectiveness of psychotherapy; in Lambert MJ (Ed). Bergin \& Garfield's Handbook of Psychotherapy and Behavior Change. New York, Wiley \& Sons, 2004, pp 139-193

14. Linden M: How to define, find, and classify side effects in psychotherapy: from unwanted events to adverse treatment reactions. Clin Psychol Psychother 2013; 20:286-296

15. Linden $M$ \& Hautzinger M: Verhaltenstherapiemanual. Berlin, Springer, 2011

16. Linden $M$ \& Muschalla B: Anxiety disorders and workplace-related anxieties. J Anx Disord 2007; 21:467-474

17. Linden $M$ \& Strauß B: (Eds). Risiken und Nebenwirkungen von Psychotherapie. Berlin, Medizinisch Wissenschaftliche Verlagsgesellschaft, 2013

18. Linden M, Walter $M$, Fritz $K \&$ Muschalla B: Unerwünschte Therapiewirkungen bei verhaltenstherapeutischer Gruppentherapie. Häufigkeit und Spektrum. Der Nervenarzt 2015; 86:1371-1382

19. Mohr DC: Negative outcome in psychotherapy. A critical review. Clinical Psychology and Scientific Practice $1995 ; 2: 1-27$

20. Muschalla B, Fay D, Jöbges M, Ayhan H, Flöge B, Heidrich $L \&$ Linden M: Evaluation of a group therapy for patients with work-related anxieties. Project report and therapy manual. Potsdam, University Potsdam and Brandenburgklinik Bernau, 2014

21. Muschalla B, Linden $M \&$ Jöbges M: Work-Anxiety and Sickness Absence After a Short Inpatient Cognitive Behavioral Group Intervention in Comparison to a Recreational Group Meeting. J Occup Environ Med 2016; 58:398-406

22. Noordik E, van der Klink JJ, Geskus RB, de Boer MR, van Dijk FJ \& Nieuwenhuijsen K: Effectiveness of an exposure-based return-to-work program for workers on sick leave du to common mental disorders: a clusterrandomized controlled trial. Scand J Work Environ Health 2013; 39:144-154

23. Kordy $H \&$ Senf $W$ : Therapieabbrecher in geschlossenen Gruppen. Psychotherapy Psychosomatic and Medical Psychology 1992; 42:127-135

24. Roback HB: Adverse outcomes in group psychotherapy. Risk factors, prevention, and research directions. $J$ Psychother Pract Res 2000; 9:113-122

25. Schermuly CC, Schermuly-Haupt ML, Schölmerich $F \&$ Rauterberg H: Zu Risiken und Nebenwirkungen lesen Sie... Negative Effekte von Coaching. Zeitschrift für Arbeits- und Organisationspsychologie 2014; 58:17-33

26. Sipos V\& Schweiger U: Gruppentherapie; in Leibing E, Hiller W, Sulz $S$ (Eds). Lehrbuch der Psychotherapie. Ausbildungsinhalte nach dem Psychotherapeutengesetz. Vertiefungsband Verhaltenstherapie. München, CIPMedien, 2003, pp 469-481

27. Smokowski PR, Rose S, Todar $K$ \& Reardon K: Postgroup-Casualty Status, Group Events, and leader 
Behavior: An Early Look Into the Dynamics of Damaging Group Experiences. Research on Social Work Practice 1999; 9:555-574

28. Strauß B \& Mattke D: Nebenwirkungen und unerwünschte Wirkungen in der Gruppentherapie; in Linden $M$, Strauß B. (Eds). Risiken und Nebenwirkungen von Psychotherapie. Berlin, Medizinisch Wissenschaftliche Verlagsgesellschaft, 2012; pp 75-85
29. Van Gent EM \& Zwart FM: Psychoeducation of partners of bipolar-manic patients. J Affect Disord 1991; 21:15-18

30. Van Vilsteren M, van Oostrom SH, de Vet HC, Franche $R L$, Boot CR \& Anema JR: Workplace interventions to prevent work disability in workers on sick leave. Cochrane Database Syst Rev 2015; 10:CD006955

31. Yalom ID \& Liebermann MA: A study of encounter group casualities. Arch Gen Psychiatry 1971; 25:16-30

Correspondence:

Prof. Beate Muschalla, MD

Technische Universität Braunschweig,

Humboldtstraße 33, 38106 Braunschweig, Germany

E-mail: beate.muschalla@gmx.de 